\title{
Firing order selection for a V20 commercial diesel engine with FEV Virtual Engine
}

The continuously increasing mechanical and thermal loads of modern engines require optimization of the designs with incorporation of a wide range of different aspects. Application of advanced computer simulations in the development process for most engine components is well established, leading to the creation of well optimized products. However, the optimization of such design variables like the firing order, which influences engine operation in several disciplines, is still challenging. Considering the ever increasing peak firing pressure requirements, the layout of the firing order in multi-cylinder commercial engines is an efficient way to reduce crank train / overall engine vibration and main bearing loads, whilst controlling engine balancing and preserving adequate gas exchange dynamics.

The proposed general firing order selection process for four-stroke engines and, in particular, its first part being the optimization of the firing order based on crank train torsional vibration, is the main topic of this paper. The exemplary study for a V20 high speed commercial Diesel engine regarding the influence of the firing sequence on crank train torsional vibration has been conducted with the multibody dynamics simulation software "FEV Virtual Engine". It addresses various engine crankshaft layouts and engine applications.

Key words: firing order, torsional vibration, commercial engine powertrain

\section{Introduction}

Selection of the firing order for typical automotive engine, having only few cylinders, is relatively simple task, since the number of alternatives is limited. However, the number of feasible firing orders rises strongly with the number of cylinders and for multi-cylinder engines having more than 12 cylinders (being currently almost exclusively commercial diesel or gas engines) it reaches thousands of possibilities. Due to this, as well as due to strong influence of the firing order on several aspects of engine operation, the selection of the firing order is since decades an engineering challenge $[3,9]$.

The exceptional increase of computational speed in the last years allows for an investigation of firing order influence to a higher extend than ever before. In particular, the torsional vibration simulation of the crankshaft in frequency domain, which may currently return the basic results of one specific case within few seconds, enables the full factorial considerations on a big set of alternative firing orders. This is especially convenient, since the application of typical optimization techniques having an algorithm, which decides how to explore the design space in order to find the optimum, is not feasible, because of the integer valued nature of the firing order as specific design variables (a set of cylinder numbers with assigned firing angles or firing intervals).

There are certain boundary conditions, which limits the above-mentioned design variable space. For typical commercial vee engines, one such is the crankshaft layout, which defines engine internal/external balancing, while enabling realization of hundreds or thousands of alternative firing sequences.

\section{Proposed firing order selection process $[5,6]$}

An overview of the proposed general firing order selection process is shown in Fig. 1. The process starts with the definition of an initial crank train design. For these basic data, alternative crankshaft layouts can be defined, including verification of engine external and internal balancing.
Subsequently, all alternative firing orders are to be generated. The set of alternative firing orders should contain only those firing orders which are possible within the considered crankshaft designs. This significantly reduces the number of cases to be subjected to further considerations.

Since in case of engines with crankshafts having several crank throws (e.g. V16 or V20 high speed commercial engines), crank train torsional vibration is one of the most challenging aspects to be controlled in engine bottom end design, the set of torsional vibration simulations in the frequency domain or 1D crankshaft simulations which additionally include quasi-static bending analysis of crank throws are to be performed subsequently. This full factorial investigation of the firing order influence is the first, torsional vibration-based, firing order optimization loop leading to a preselected set of beneficial firing orders.

Following the selection process, the preselected firing orders are to be subjected to further engine concept analyses which are hydrodynamic bearing simulation and gas dynamics simulation in the intake and exhaust ducts. As a result, a second firing order optimization loop is performed. In the last step, one or few final firing orders are to be considered in the time consuming detailed design engine simulations, to finally confirm the proper selection of the optimal firing order. This includes the analysis of crankshaft axial vibration being a new rising concern in development of high speed commercial engines [1].

Within such a firing order selection process, several backward loops are possible, including revision of base engine dimensions and change of the optimization objective targets.

The Firing Order Investigation Tool, enabling the investigation according to above-mentioned methodology, is already implemented for commercial software "FEV Virtual Engine". In its initial form, it allows the end user to automatically generate alternative firing orders for the predefined crankshaft layout, to run series of 1D crankshaft simulations by application of a known and proven functionality called Crank Concept Analysis and to evaluate the. 


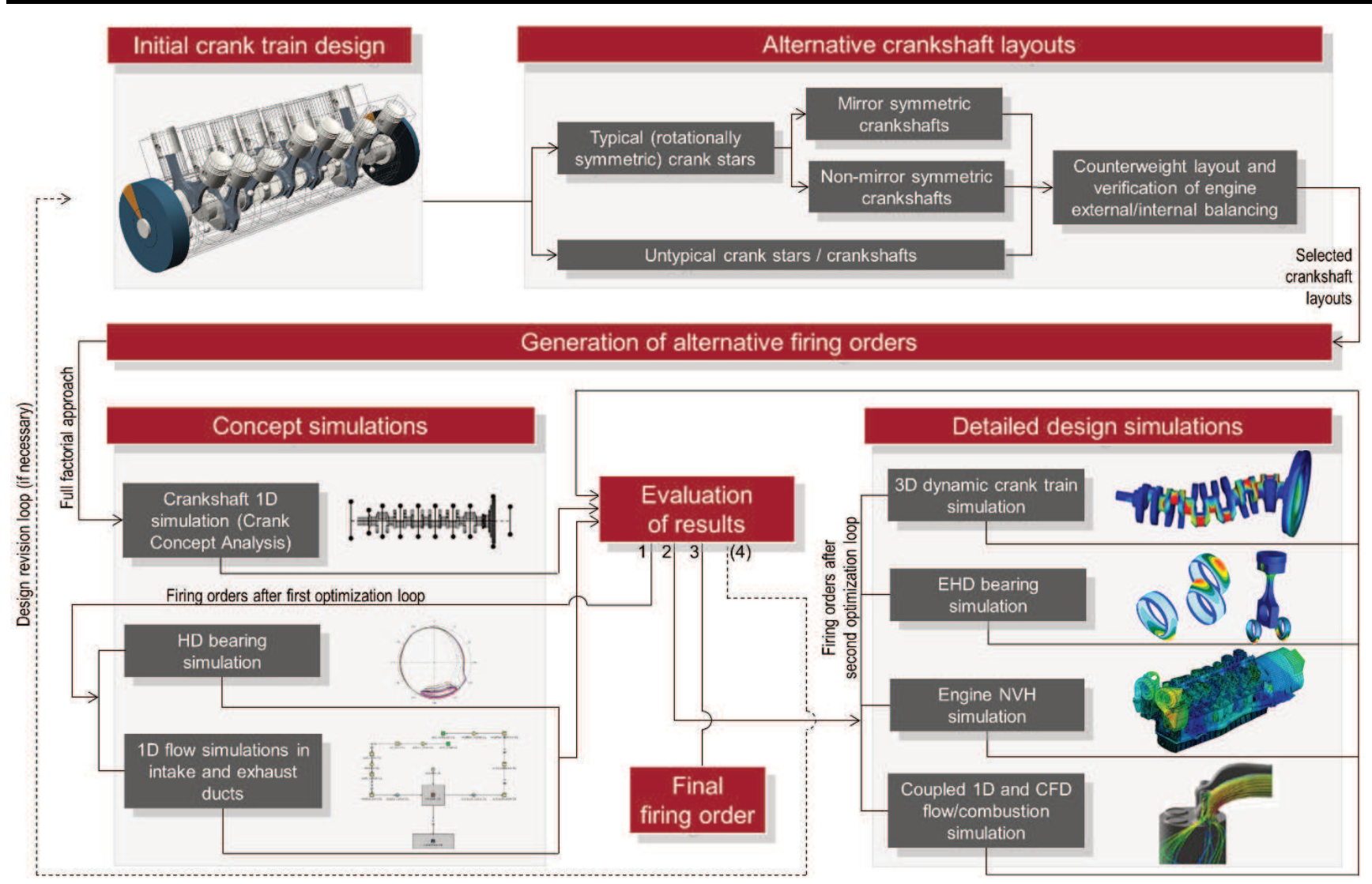

Fig. 1. General firing order selection process

results by use of multi-criteria optimization techniques popularized by Derringer and Suich [10The alternative firing orders are determined by execution of a specialized algorithm, which predecessor has been described in [4]. The procedure implemented for the "FEV Virtual Engine" has been significantly improved, enabling the generation of all feasible firing sequences for any defined crankshaft layout and engine configuration.

\section{Exemplary investigation of the firing order in- fluence on crank train torsional vibration}

The above-mentioned approach has been applied in order to investigate the influence of the firing order in an exemplary V20 four-stroke high speed commercial Diesel engine taking into account torsional vibration aspects. The considered engine has a bore of $180 \mathrm{~mm}$, a bank angle of 60 degrees and a rated speed of $1900 \mathrm{rpm}$. The crankshaft base dimensions have been defined basing on experience from development of engines of similar size and type in order to enable safe crankshaft operation with a peak cylinder pressure of 240 bar.

The influence of the firing order on crankshaft torsional vibration was investigated considering typical crankshaft layouts having rotationally symmetric crank stars and lengthwise mirror symmetric arrangement of crank throws (so called fully symmetric crankshafts). Such approach ensures inherent engine external balancing and minimizes engine torque fluctuations. The marine engine application with torsionally highly elastic flywheel coupling and an appropriately tuned leaf spring type torsional vibration damper was taken into account.
The applied crank train torsional vibration excitation due to gas forces for various engine speeds corresponds to a so-called overload propeller curve.

\subsection{Number of considered crankshaft layouts and firing} orders

The number of feasible firing orders for the considered V20 engine has been determined by use of equation (1):

$$
\mathrm{n}_{\mathrm{FO}}=2^{\left(\frac{\mathrm{n}_{\mathrm{CT}}}{2}-1\right)} \cdot\left[2^{\left(\frac{\mathrm{n}_{\mathrm{CT}}}{2}\right)}\right]^{\left(\mathrm{n}_{\mathrm{b}}-1\right)} \cdot\left(\frac{\mathrm{n}_{\mathrm{CT}}}{2}-1\right) !
$$

where $\mathrm{n}_{\mathrm{CT}}$ is number of crank throws and $\mathrm{n}_{\mathrm{b}}$ is the number of engine banks. The equation (1) can be applied for any typical engine configuration having fully symmetric crankshaft. It consists of three general parts:

$$
\left.\mathrm{n}_{\mathrm{FO}}=\mathrm{n}_{\mathrm{FO} \mathrm{i}, 1} \cdot\left[\mathrm{n}_{\mathrm{FO}}\right]_{\mathrm{j}}\right]^{\left(\mathrm{n}_{\mathrm{b}}-1\right)} \cdot \mathrm{n}_{\mathrm{csh}}
$$

which describes accordingly: number of firing orders in first cylinder bank $\mathrm{n}_{\mathrm{FO}_{\mathrm{i}, 1}}$, number of firing orders in next cylinder bank(s) $n_{\mathrm{FO}}, j$ and number of possible crankshaft layouts $\mathrm{n}_{\mathrm{csh}}$.

The results of application of equation (1) for the considered V20 engine are summarized in Table 1. A V12, V16 and V24 engines have been added for a reference. 
Table 1. Number of alternative firing orders for a VEE engines with fully symmetric crankshaft layouts

\begin{tabular}{|c|c|c|c|c|c|}
\hline \multirow{2}{*}{$\begin{array}{c}\text { Engine } \\
\text { type }\end{array}$} & \multicolumn{3}{|c|}{$\begin{array}{l}\text { Number of firing orders for } \\
\text { single crankshaft layout }\end{array}$} & \multirow{2}{*}{$\begin{array}{c}\text { Number of } \\
\text { crankshaft } \\
\text { layouts }\end{array}$} & \multirow{2}{*}{$\begin{array}{c}\text { Total num- } \\
\text { ber of firing } \\
\text { orders }\end{array}$} \\
\hline & $\begin{array}{l}\text { in first } \\
\text { bank }\end{array}$ & $\begin{array}{c}\text { in second } \\
\text { bank }\end{array}$ & total & & \\
\hline V12 & 4 & 8 & 32 & 2 & 64 \\
\hline V16 & 8 & 16 & 128 & 6 & 768 \\
\hline V20 & 16 & 32 & 512 & 24 & 12288 \\
\hline V24 & 32 & 64 & 2048 & 120 & 245760 \\
\hline
\end{tabular}

\subsection{Evaluation of crankshaft layouts and balancing concept}

Since the study has been reduced to fully symmetric crankshaft layouts, all 24 considered crankshafts for V20 engine are externally inherently balanced. However, relative angular arrangement of a consecutive crank throws have significant influence on a crankshaft internal balancing. An internal bending moment caused either by rotating or oscillating forces bends the crankshaft during rotation, resulting in an increased bearing loads. Therefore, the evaluation of crankshaft layout has been performed considering crankshaft internal balancing determined acc. to approach described in [2].

The course of non-dimensional internal bending moment caused by rotating masses over crankshaft length for two selected crankshaft layouts is shown in Fig. 2 and Fig. 3 . In both cases, the internal bending moments have been determined prior to the application of counterweights, which enables evaluation of the inherent internal unbalance.

The crank throw arrangement in crankshaft layout No. 15 depicted in Fig. 2 leads to small bending in the parallel $\left(\mathrm{Mb}_{\mathrm{XZ} \text {-un }}\right)$ as well as in perpendicular $\left(\mathrm{Mb}_{\mathrm{YZ}-\text { un }}\right)$ plane to the first crank throw. Therefore, the maximum of the nondimensional resultant bending moment $\left(\mathrm{Mb}_{\text {tot-un }}\right)$ over crankshaft length with a value of 1.29 is also on the low level (the lowest over all considered crankshafts).

Contrary to the above-mentioned crankshaft layout, the crankshaft layout No. 4, depicted in Fig. 3, leads to significant bending in plane parallel to the first crank throw $\left(\mathrm{Mb}_{\mathrm{XZ} \text {-un }}\right)$. The maximum value of non-dimensional resultant bending moment $\left(\mathrm{Mb}_{\text {tot-un }}\right)$ equal to 4.98 is the biggest over all considered crankshafts and almost four times bigger than in case of crankshaft layout No. 15.

The Table 2 summarizes the considerations regarding crankshaft internal balancing of fully symmetric crankshafts due to rotating masses, showing 3 best and 3 worst crankshaft layouts.

The internal bending of the crankshaft due to rotating masses can be noticeably reduced or even cancelled out by appropriate counterweight layout. For the purpose of this paper, a most straightforward and a historically proven counterweight layout have been applied, where each crank throw is balanced separately by two counterweights. The balancing ratio of $100 \%$ has been chosen. Therefore, the internal bending due to rotating masses has been eliminated and internal bending due to oscillating masses has remained unchanged for all 24 considered crankshaft layouts. Since in the considered engine the internal bending due to first order oscillating masses follows similar rules as in case of already considered rotating masses, the evaluation shown in Table 2 can be directly extrapolated to final engine internal balancing.

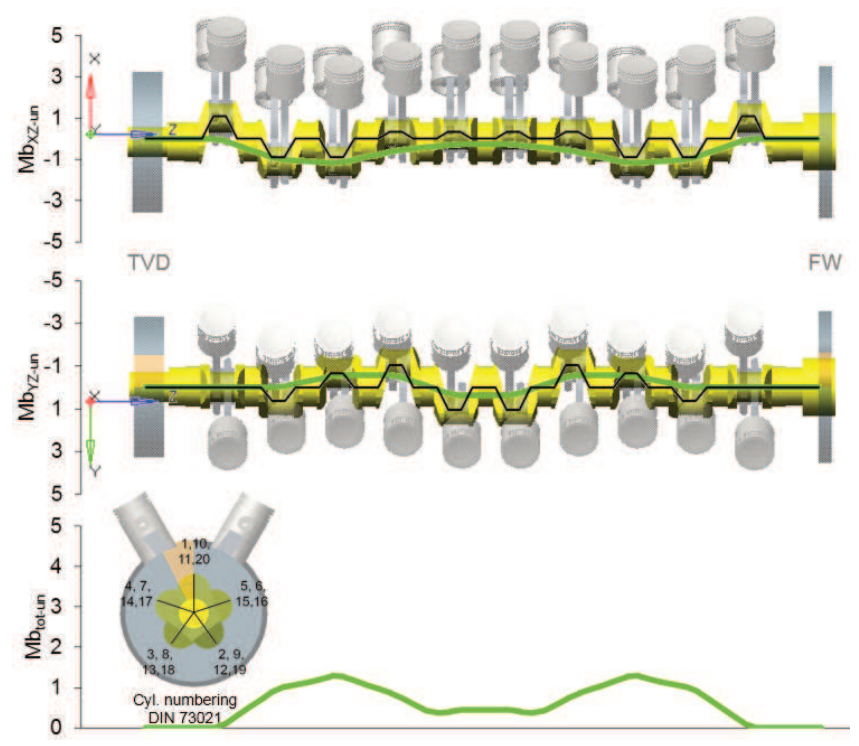

Fig. 2. Non-dimensional internal bending moment due to rotating masses of crankshaft layout No. 15

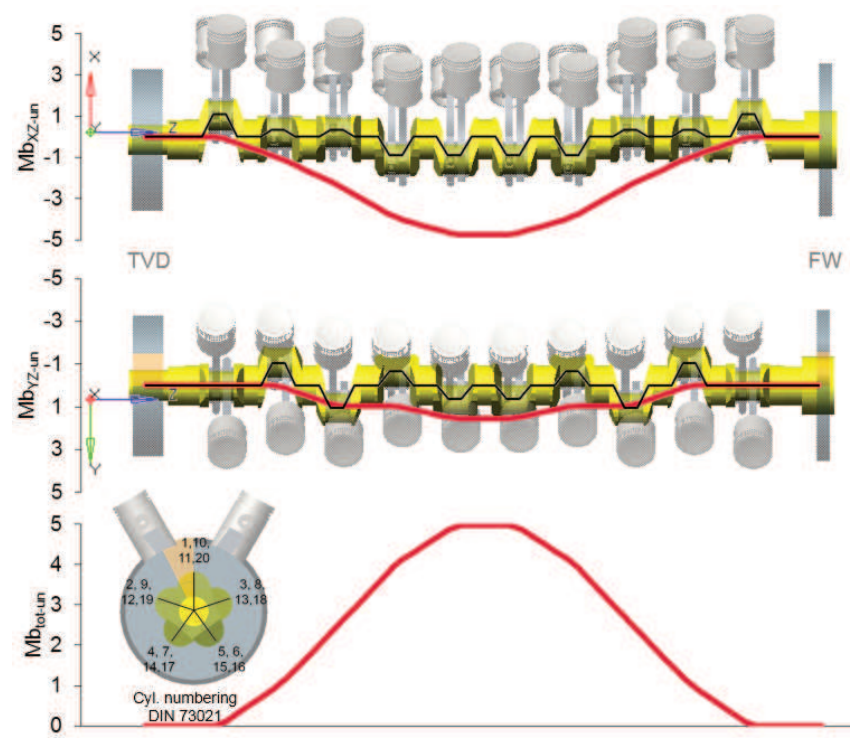

Fig. 3. Non-dimensional internal bending moment due to rotating masses of crankshaft layout No. 4

The applied counterweight layout compromises crankshaft weight and therefore crankshaft natural frequencies of torsional and axial eigenmodes are relatively low. The same balancing effect can be obtained by smaller number/size of counterweights but it requires optimization of counterweight layout for each considered engine and crankshaft configuration. Therefore, the balancing of each crank throw separately is still preferred by some engine manufacturers since it simplifies crankshafts designs during development of commercial engine family. For the firing order investigation, such approach is also a convenient starting point, since mass moment of inertia of each lump mass in crankshaft torsional 1D model remains unchanged for any crankshaft layout. 
Table 2. Peak non-dimensional internal bending moments for selected crankshaft layouts

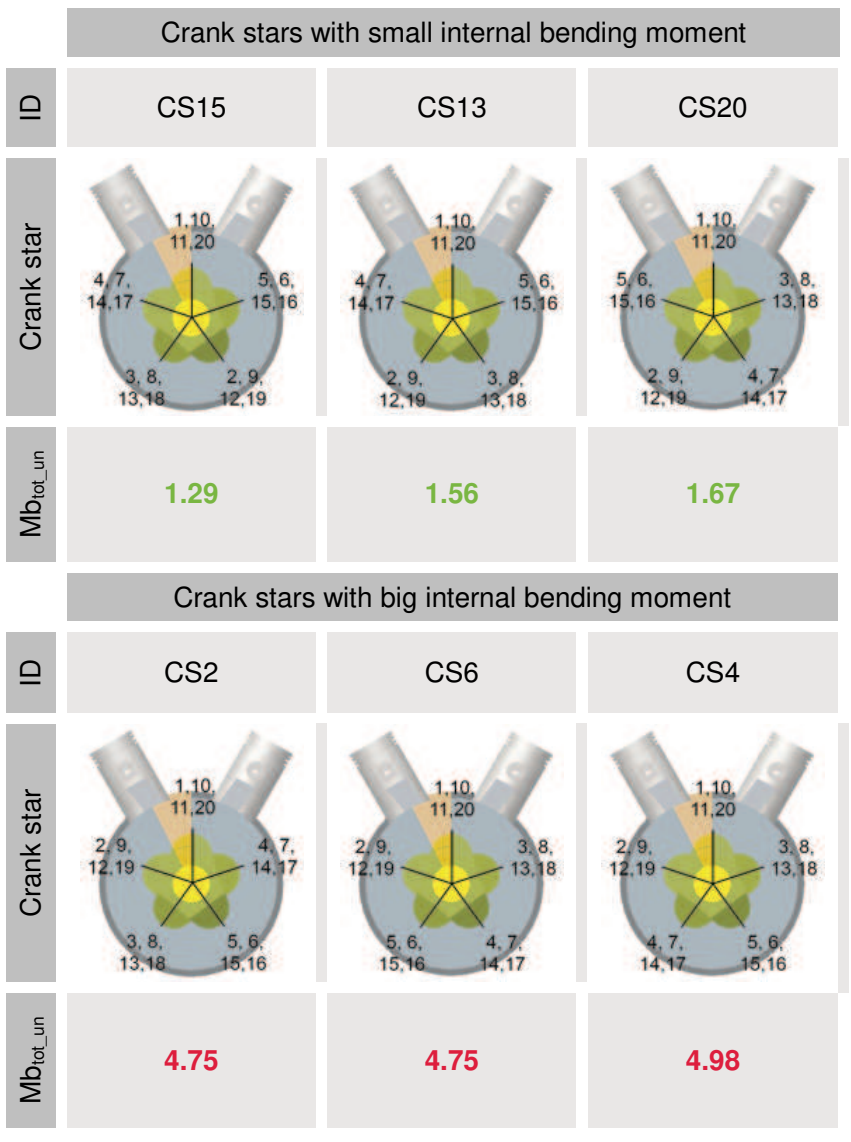

Remark: cylinder numbering acc. to DIN 73021

It is to be mentioned, that application of semisymmetric crankshafts (having rotationally symmetric crank stars but no lengthwise mirror symmetric arrangement of crank throws) becomes to be an interesting alterna- tive for current, highly loaded multi-cylinder commercial engines [8]. Regardless of introduction of usually unavoidable engine external unbalance and required comprehensive balancing investigations, they may finally lead to good compromise between all crankshaft and firing order related aspects. The additional balancing topics for semi-symmetric crankshafts are introduction of crankshaft intentional unbalance as well as verification of balancing potential by balancing drillings, which are required to ensure feasibility to remove crankshaft unbalance caused by forging and manufacturing tolerances in a dedicated counterweights on a balancing machine.

\subsection{Torsional vibration damper tuning [6]}

For the considered engine, the engine speed of the highest torsional vibration excitation due to gas forces is between 1700 and $2000 \mathrm{rpm}$. Especially in this speed range, excessive vibration should be avoided either by system tuning, appropriate damping or reduction of the resultant excitation of selected eigenmodes by proper phasing of excitation caused by individual cylinders. The means for the first two points are provided by the application of the leaf spring damper, while the last one can be addressed by appropriate selection of the firing order.

The layout of the leaf spring damper has been performed taking into account in parallel the physical damper limitations and possible further influence by the firing order alteration. Regarding the damper size, the mass moment of inertia of the outer part was defined as less than $45 \%$ of the complete crank train mass moment of inertia without a damper. The selected stiffness of the damper, which is in the middle of the known range, leads to the split of the $1^{\text {st }}$ crank train eigenmode into two crank train - damper modes, with natural frequencies being possibly far from one another. This effect is shown in Fig. 4.



Fig. 4. Leaf spring damper tuning prior to the firing order influence investigation

For the considered engine with any fully symmetric crankshaft, taking into account lower excitation harmonic orders which are the strongest, the alteration of a firing order influences the resultant excitation of the $1.5^{\text {th }}, 2.5^{\text {th }}$ and $3.5^{\text {th }}$ order. With the applied damper tuning, these resonances have been moved out of the engine speed range of 
high torsional vibration excitation of each single engine cylinder (from 1700 to $2000 \mathrm{rpm}$ ).

The only resonance, which according to the Campbell diagram may occur in the above-mentioned speed range is the resonance of the $3^{\text {rd }}$ excitation harmonic order with the $2^{\text {nd }}$ crank train - damper mode $(88 \mathrm{~Hz})$. However, due to the combination of the selected engine bank angle and the mirror symmetry of the crankshaft, regardless of the chosen firing order, the resultant torsional vibration excitation of this eigenmode is zero for the $3^{\text {rd }}$ excitation harmonic order.

\subsection{Influence of the firing order on crank train torsion- al vibration}

The influence of a firing order on crank train torsional vibration of the considered V20 engine has been analyzed by use of conceptual firing order investigation tools, which uses FEV Virtual Engine's Crank Concept Analysis as a 1D crankshaft simulation solver. The torsional vibration simulations of the crankshaft have been performed for a determined 12288 alternative firing orders (512 per each of 24 crankshaft layouts) on a currently available business class PC in about 6 hours of computational time by use of multiprocessing (8 parallel processes).

The tolerable torsional vibration level of the crank train is limited in relation to several aspects. The most important

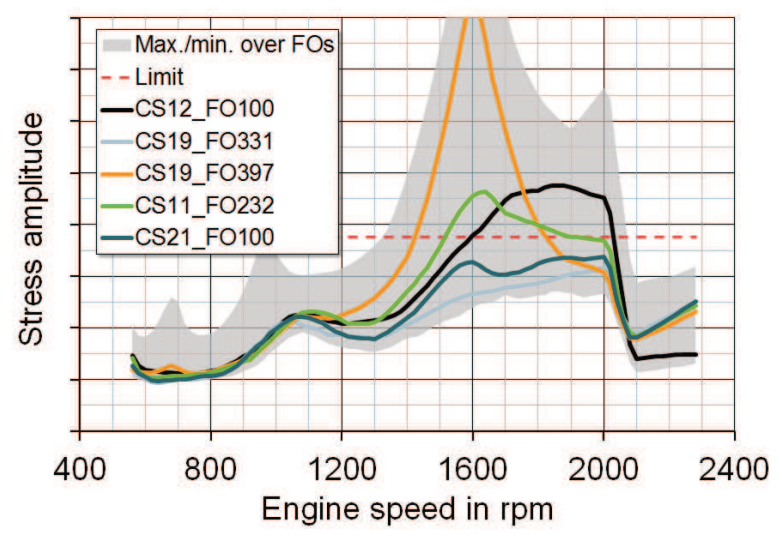

Fig. 5. Crankshaft nominal vibratory stress amplitude (synthetized) for historical firing orders

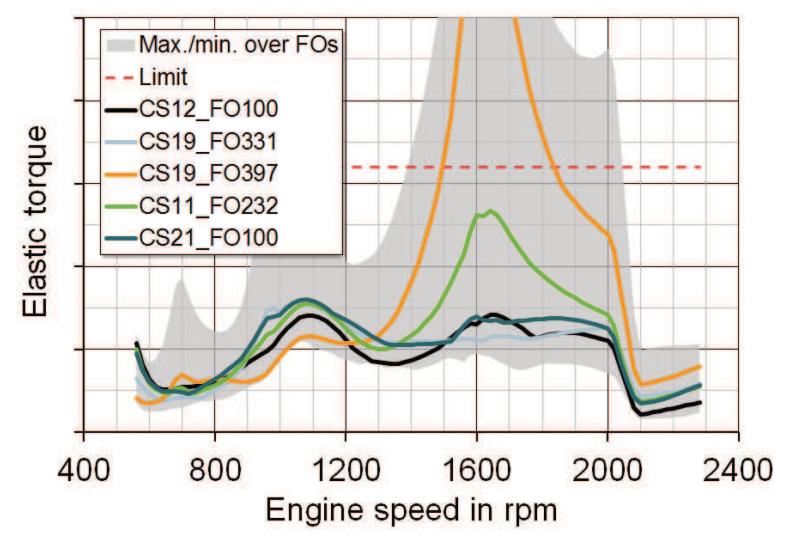

Fig. 7. Torsional vibration damper elastic torque for historical firing orders are crankshaft fatigue strength, design limitations of the torsional vibration damper, couplings, driven system(s) and accessory drives [7]. For the purpose of this paper, the presented signals are reduced to the crankshaft nominal vibratory stress amplitude and the torsional vibration damper load. The figures are divided into two groups, where the first one (Figure 5 to 8 ) depicts the results of historical firing orders from engine literature [3,9] or a known engines and the second one (Figure 9 to 12) depicts the optimized results derived by multi-criteria optimization according to weighted desirability function approach popularized by Derringer and Suich [10].

All above-mentioned figures involve the so-called "Max./min. over FOs" zone which is defined by the upper and lower envelope of all simulation results. The zones show a strong influence of the firing order on the resultant torsional vibration excitation of the $1^{\text {st }}$ eigenmode by the $1.5^{\text {th }}, 2.5^{\text {th }}$ and $3.5^{\text {th }}$ excitation harmonic order, as well as not fully developed due to fuel cut-off resonance of the $2^{\text {nd }}$ eigenmode with the $2.5^{\text {th }}$ excitation harmonic order and the $3^{\text {rd }}$ eigenmode with the $4.5^{\text {th }}$ excitation harmonic order. The resonance of the $1^{\text {st }}$ eigenmode with the $1.5^{\text {th }}$ excitation harmonic order is exceptionally strong, therefore it was depicted separately in Figure 6 and 10.

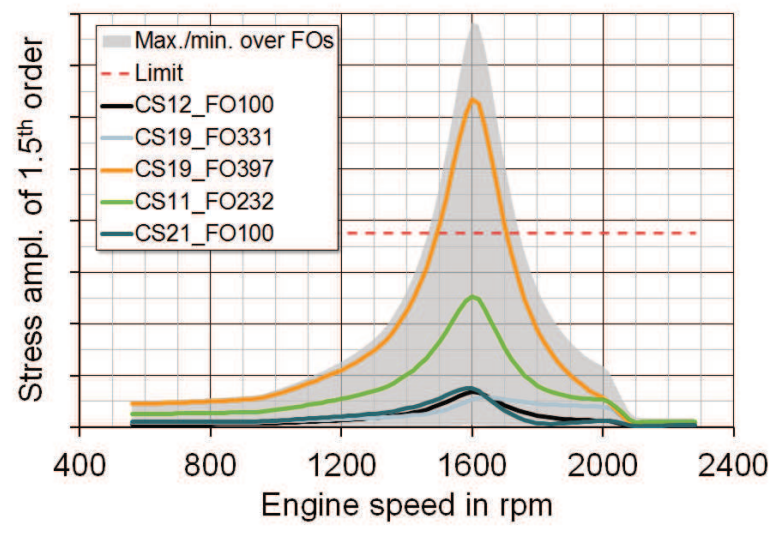

Fig. 6. Crankshaft nominal vibratory stress amplitude (1.5th order) for historical firing orders

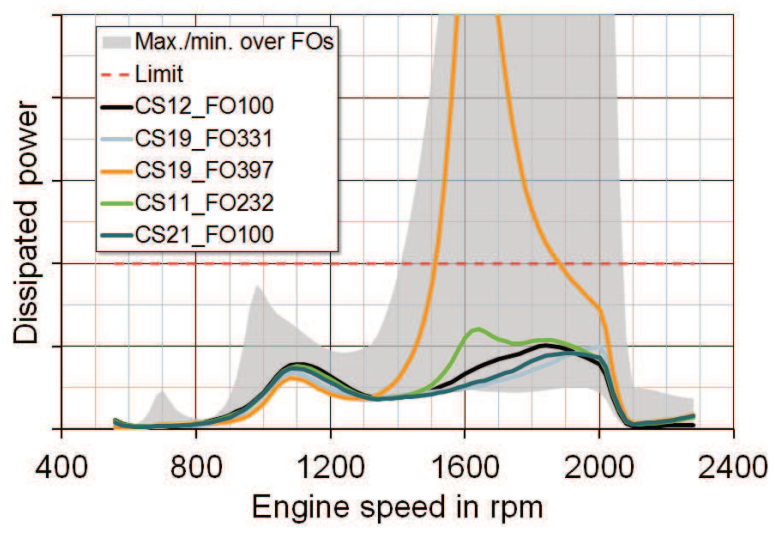

Fig. 8. Torsional vibration damper dissipated power for historical firing orders 


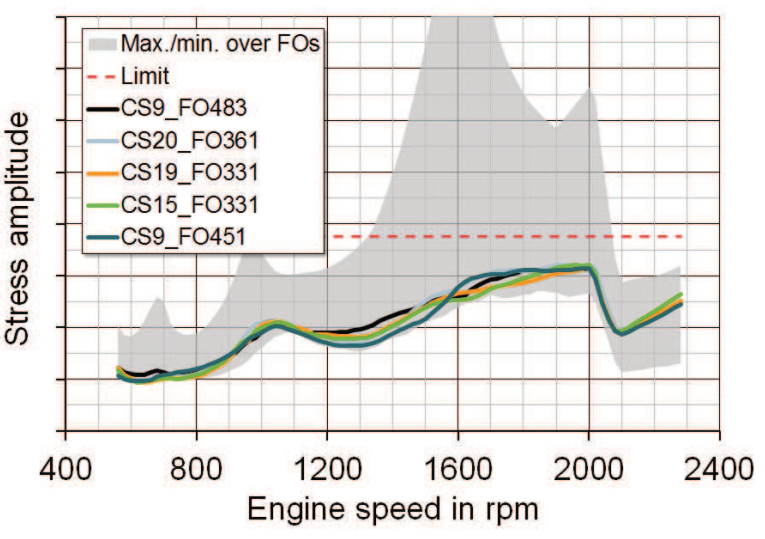

Fig. 9. Crankshaft nominal vibratory stress amplitude (synthetized) for optimum firing orders

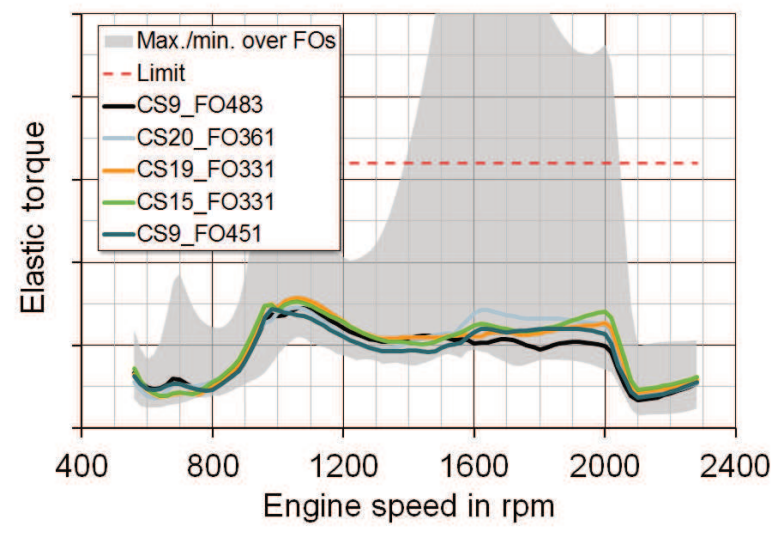

Fig. 11. Torsional vibration damper elastic torque for optimum firing orders

The two from depicted historical firing orders, CS19_FO331 (crank star No. 19, firing order No. 331) and CS21_FO100 enables to satisfy the criteria for nominal vibratory stress amplitude of the crankshaft but only CS19_FO331 passed the multi-criteria optimization. In case of firing order CS19_FO397 and CS11_FO232, exceeding the limit of crankshaft nominal vibratory stress is caused by strong vibration according to the $1^{\text {st }}$ eigenmode excited by the $1.5^{\text {th }}$ harmonic order, while in case of firing order CS12_FO100, this is caused by the common contribution of the resonance of the $3^{\text {rd }}$ eigenmode with $5^{\text {th }}, 5.5^{\text {th }}$ and $6^{\text {th }}$ excitation harmonic order.

The only 35 from 12288 firing orders were able to satisfy all of the considered vibratory and engine balancing limits. The results for the 5 most beneficial firing orders per crankshaft layout are shown individually in Figures 9 to 12. They are listed in the chart legend in ascending order (the firing order CS9_FO451 has the biggest value of the desirability function).

All of the beneficial firing orders leads to low crankshaft nominal vibratory stress amplitude (Fig. 9) and weakly excites the vibration according to the $1^{\text {st }}$ eigenmode by the $1.5^{\text {th }}$ harmonic order (Fig. 10). In addition, the damper load (Fig. 11 and 12) is also in the lower range. It is worth to notice, that historical firing order CS19_FO331 is in one of top 5 firing orders.

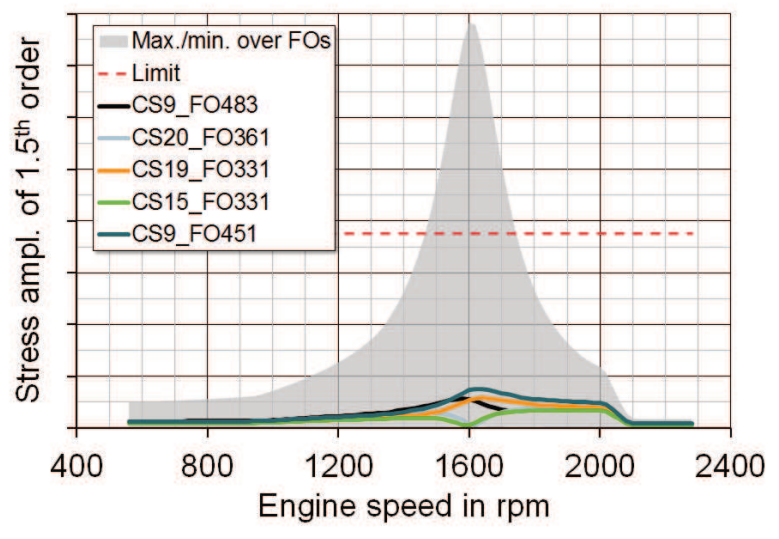

Fig. 10. Crankshaft nominal vibratory stress amplitude (1.5th order) for optimum firing orders

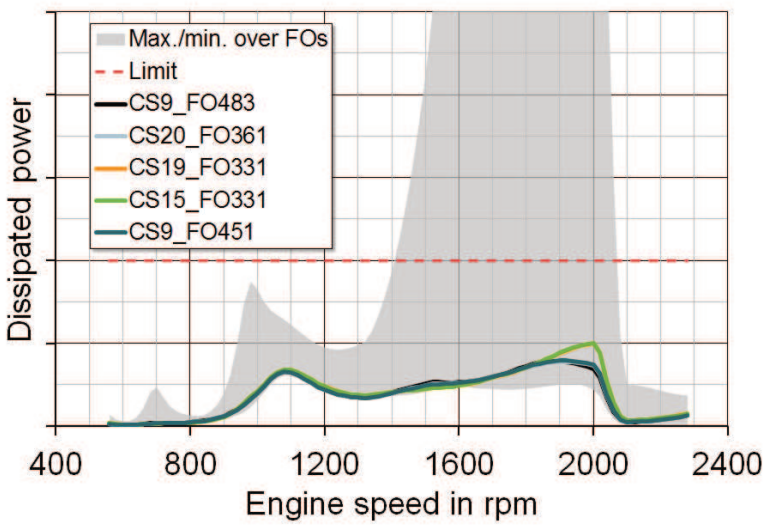

Fig. 12. Torsional vibration damper dissipated power for optimum firing orders

\section{Summary}

The torsional vibration part of the proposed firing order selection process has been performed for the purpose of this paper on an exemplary V20 high speed commercial Diesel engine. The taken into consideration aspects of engine balancing, torsional vibration damper tuning, definition of the number of alternative firing orders and crankshaft torsional vibration simulation depicts the significance and the complexity of this engineering challenge already in the concept phase of an engine development.

The results prove the sensitivity of the resultant torsional vibration excitation of crank train eigenmodes by particular excitation harmonic orders for different firing orders. From over 12000 of alternative firing sequences feasible to be realized by 24 fully symmetric crankshaft layouts (typical crankshafts for V20 engines), only 35 firing orders were able to satisfy all crankshaft torsional vibration and balancing criteria. Such preselection supported by multi-criteria optimization gives a good basis for further concept and detailed design simulations.

Applicability of historical firing orders for current highly loaded high speed commercial engines have been exceptionally considered. It was indicated, that historical firing orders might not be an optimum choice for a newly developed engines and detailed firing order optimization be- 
comes an important part of commercial engine development.

The basic functionality of the conceptual firing order investigation tools which applications have been briefly presented in the paper is already implemented for a commercial multi-body simulation software "FEV Virtual Engine". It allows the firing order investigation based on crankshaft 1D simulation. The list of alternative firing orders feasible to be realized by pre-defined crankshaft layout is generated by dedicated algorithm. The obtained results can be subsequently analyzed in the evaluator which allows multi-criteria optimization according to weighted desirability function approach.

\section{Acknowledgements}

Authors would like to thank Dr. Ir. Antonius Voncken (FEV Europe $\mathrm{GmbH}$ ), Dipl.-Ing. Michael Heinen (FEV Europe GmbH), Dipl.-Ing. Carsten Thorenz (FEV Europe $\mathrm{GmbH}$ ) and M.Sc. Eng. Maciej Bartosik (FEV Polska Sp. z o.o.) for their valuable contribution in the development of procedures and methods supporting the firing order optimization process.

\section{Nomenclature}

CS crankshaft/crank star

FO firing order

FW flywheel

TVD crankshaft torsional vibration damper

\section{Bibliography}

[1] MOKDAD, B., HENNINGER, C. Avoiding Crankshaft Axial Vibrations: Influencing Parameters, Simulation and Solutions. 25th Aachen Colloquium Automobile and Engine Technology. 2016.

[2] MAASS, H., KLIER, H. Die Verbrennungskraftmaschine, Band 2: Kräfte, Momente und deren Ausgleich in der Verbrennungskraftmaschine. Springer. 1981.

[3] SCHEUERMEYER, M. Einfluß der Zündfolge auf die Drehschwingungen von Reihenmotoren. Technical University of Munich. 1932.

[4] BUCZEK, K., LAUER, S. Firing order optimization in FEV Virtual Engine. Torsional Vibration Symposium. 2014.

[5] BUCZEK, K., LAUER, S. Firing order optimization in FEV Virtual Engine. Cimac Congress. 2016.

[6] BUCZEK, K., LAUER, S. Firing order selection for commercial engines with FEV Virtual Engine. Torsional Vibration Symposium. 2017.

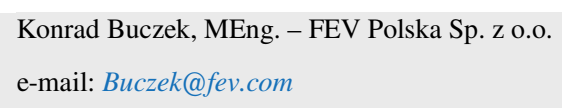

[7] HENNINGER, C. Firing sequence optimization for a V20 cylinder diesel engine. Torsional Vibration Symposium. 2014.

[8] MOKDAD, B., HENNINGER, C. Irregularity instead of harmony - Ways to improve torsional performance of a V20 engine. Torsional Vibration Symposium. 2017.

[9] WILSON, W.K., Practical solution of torsional vibration problems. John Wiley \& Sons Inc. 1942

[10] MYERS, R.H., MONTGOMERY, D.C., ANDERSONCOOK, M.C. Response surface methodology: process and product optimization using designed experiments. Wiley Series in Probability and Statistics. 2009.



